Journal of Patient-Centered

\title{
Lead Burden as a Factor for Higher Complication Rate in Patients With Implantable Cardiac Devices
}

Christopher Kolibash

Naoyo Mori

Jasbir Sra

Masood Akhtar

M. Eyman Mortada

Follow this and additional works at: https://aah.org/jpcrr

Part of the Cardiology Commons, Cardiovascular Diseases Commons, Cardiovascular System Commons, and the Equipment and Supplies Commons

\section{Recommended Citation}

Kolibash C, Mori N, Sra J, Akhtar M, Mortada ME. Lead burden as a factor for higher complication rate in patients with implantable cardiac devices. J Patient Cent Res Rev. 2015;2:17-24. doi: 10.17294/ 2330-0698.1022

Published quarterly by Midwest-based health system Advocate Aurora Health and indexed in PubMed Central, the Journal of Patient-Centered Research and Reviews (JPCRR) is an open access, peer-reviewed medical journal focused on disseminating scholarly works devoted to improving patient-centered care practices, health outcomes, and the patient experience. 


\title{
Lead Burden as a Factor for Higher Complication Rate in Patients With Implantable Cardiac Devices
}

\author{
Christopher Kolibash, MD, ${ }^{1}$ Naoyo Mori, PhD, ${ }^{2}$ Jasbir Sra, MD, ${ }^{1}$ Masood Akhtar, MD, ${ }^{1}$ \\ M. Eyman Mortada, MD' \\ ${ }^{1}$ Aurora Cardiovascular Services, Aurora Sinai/Aurora St. Luke's Medical Centers, University of Wisconsin School of \\ Medicine and Public Health, Milwaukee, WI \\ ${ }^{2}$ Center for Urban Population Health, University of Wisconsin-Milwaukee, Milwaukee, WI
}
Purpose Lead revisions have increased over the last decade. Patients who do not undergo lead extraction face an increased lead burden. Consequences of increased lead burden have not been fully defined. We sought to characterize the complication rate and outcomes in patients with sterile redundant leads.

Methods We retrospectively reviewed 242 consecutive patients [mean age $74 \pm 12$ years; $66.9 \%$ male] who underwent lead revision that resulted in an abandoned lead from January 2005 to June 2010. Patients were placed in a cohort based on number of leads after last recorded procedure (Group A: $\leq 2$ [n=58]; Group B: 3-4 [n=168]; Group C: $\geq 5$ [n=16]). Prespecified inhospital and long-term follow-up events were compared. Mortality rates were obtained from Social Security Death Index. Median follow-up was 2 years.

Results Baseline age, gender and race demographics were similar among the three groups. Increasing lead burden was associated with more adverse periprocedural events (A: $3.4 \%, B: 10.1 \%, C: 25.0 \%$; $P=0.031)$ and long-term device-related events (A: $1.7 \%, B: 13.0 \%, C: 18.8 \% ; P=0.031)$. Device-related readmissions increased in frequency as lead burden increased (A: $3.5 \%, B: 18.5 \%, C: 37.5 \% ; P=0.002)$. Combined periprocedural and late events also increased with more redundant leads (A: $5.2 \%, B: 23.2 \%$, C: $44.0 \% ; P=0.001)$. Major events were infrequent $(3.3 \%)$. There was no procedure-related mortality. Long-term all-cause mortality was not significantly different (A: $17.2 \%, B: 23.8 \%, C: 25.0 \% ; P=0.567$ ).

Conclusions Greater lead burden was associated with increased number of periprocedural and long-term minor events. It did not significantly impact major events or mortality. ( $J$ Patient-Centered Res Rev. 2015;2:17-24.)

Keywords abandoned leads, implantable cardioverter-defibrillator, pacemaker, lead revision, complications, mortality

The use of cardiac rhythm management devices has increased dramatically over the last decade, with more than 486,000 new devices implanted from 2006 to $2009 .{ }^{1}$ The established success of these devices in multiple clinical trials, particularly in the setting of cardiomyopathy, has expanded the indications for device therapy and increased the number of patients who qualify for them. ${ }^{2}$ With the success of medical and device therapy in the treatment of cardiovascular disease, patients are living long enough to benefit from increasingly sophisticated device upgrades (e.g.

Correspondence: M. Eyman Mortada, MD, 2801 W. Kinnickinnic River Parkway, Suite \#840, Milwaukee, WI, 53215, T: 414-649-3909, F: 414-649-3551, Email: publishing4@aurora.org biventricular pacing and defibrillation capability), which require the introduction of additional leads. Many patients now outlive the functional life of their implanted hardware and require replacement of nonfunctioning leads. Once a device has been replaced or upgraded, a decision has to be made as to whether existing leads should be extracted or revised (i.e. capped and secured, leaving an abandoned lead in place). Lead extraction is defined as removal of the lead, regardless of the duration of the implant, using specialized equipment not included in a typical implant package. ${ }^{3}$ Lead extraction may require emergent cardiac surgery and carries a mortality risk of $0.4-0.8 \% .{ }^{4}$ Due to the extremely high rate of mortality and morbidity associated with device and/or lead infection, extraction of infected leads as the optimal management strategy is not debated. However, only $60 \%$ of leads extracted are 
in response to infection, and $40 \%$ of extracted leads are sterile and merely superfluous. ${ }^{5}$

Extraction of sterile redundant leads is controversial. Arguments for extracting these leads are based on maintaining future central venous access options and to prevent potential complications, including venous thrombosis, lead migration, infection, lead-lead interaction, tricuspid regurgitation and venous or cardiac chamber perforation. However, the frequency of these complications is not well-defined in the literature. Moreover, the efficacy of intervening to prevent these complications is not well-documented. The purpose of this study was to characterize complication rates and potential outcomes in patients with sterile redundant leads.

\section{METHODS}

After institutional review board approval, we retrospectively reviewed 242 consecutive patients (mean age $74 \pm 12$ years; 66.9\% male) who underwent a lead revision procedure that resulted in an abandoned lead from January 2005 to June 2010 at our facility. This patient population represented $3.75 \%$ of the total patient population that underwent device implantation at our facility during the study period $(\mathrm{N}=6,451)$. Our main inclusion criterion was that a patient underwent any lead revision procedure resulting in at least one abandoned lead. Patients who had a lead removed either by manual traction during device revision/ upgrade or through a lead extraction procedure for a sterile redundant lead, leaving no superfluous leads, were excluded. Patients with implantable cardioverterdefibrillator (ICD) leads and/or pacemaker leads were included. Patients were placed in one of three cohorts based on total number of functional and abandoned leads present after their last recorded device-related procedure (Group A: $\leq 2$ leads [n=58]; Group B: 3 or 4 leads [n=168]; Group C: $\geq 5$ leads [n=16]).

The groups were compared based on age, gender and comorbidities (Table 1). Indications for device upgrade and lead abandonment were reviewed in the medical record (Table 1). The cohorts were compared to determine whether number of leads (escalating level of lead burden) affected prespecified endpoints in regard to outcomes. Because actual individual events were infrequent, we compared outcomes that were prespecified: inhospital and periprocedural events, device-related readmissions and long-term follow-up events. Inhospital and periprocedural events associated with the abandonment of a lead included pneumothorax, bleeding/hematoma, spontaneous unstable procedural arrhythmias requiring treatment, central venous or cardiac perforation, failure to place a new lead, failure to attain adequate defibrillation thresholds requiring additional intervention, venous thrombosis requiring change of strategy for new lead implantation (i.e. venoplasty, tunneling, contralateral access) and death. Long-term events (after 30 days of procedure) included late bleeding, cardiac or central venous perforation, venous thrombosis, inappropriate ICD shock, atrial arrhythmia, device-related infection and death. Device-related readmissions were documented through analysis of the medical record. Mortality rates were obtained from the Social Security Death Index. Overall median follow-up was 2.0 years (with interquartile range of 1.1-3.5).

\section{Statistical Analysis}

Continuous variables are summarized as medians with interquartile range. Discrete variables are described as counts with percentages. Differences among the three study groups $(\leq 2,3-4$ and $\geq 5$ leads) were tested using Kruskal-Wallis test or Wilcoxon rank-sum test for continuous variables and chi-square/Fisher's exact tests with 95\% confidence levels (two-tailed) for discrete variables.

\section{RESULTS}

During the study period, 242 patients met the inclusion criteria $(3.75 \%$ of the total number of patients receiving cardiac rhythm management device implants or lead revision at our facility). The study population included 162 men and 80 women (mean age 74 years); $75.2 \%$ of patients $(n=182)$ were older than 65 years. There was no significant difference among the groups with regard to gender or mean age. There was a statistically significant difference in the number of patients older than 65, as Group A (patients with $\leq 2$ leads) had fewer of these patients compared with the other two groups (A: $58.6 \%$, B: $80.4 \%$, C: $81.3 \% ; \mathrm{P}=0.004$ ). At baseline, patients in each group had similar rates of coronary artery disease, diabetes, atrial arrhythmia and dialysis. Hypertension (A: 37.9\%, B: 60.0\%, $\mathrm{C}: 68.0 \% ; \mathrm{P}=0.007)$ and prior congestive heart failure (A: $62.1 \%, B: 78.0 \%, C: 87.5 \% ; \mathrm{P}=0.027$ ) were 
Table 1. Baseline patient characteristics and indications for original lead revision and abandonment

\begin{tabular}{|c|c|c|c|c|c|}
\hline \multirow[b]{2}{*}{ Variable } & \multirow[b]{2}{*}{$\begin{array}{l}\text { Overall } \\
(\mathrm{N}=242)\end{array}$} & \multicolumn{4}{|c|}{ Body surface area, $\mathrm{m}^{2}$} \\
\hline & & $\begin{array}{c}\leq 2 \\
(n=58,24.0 \%)\end{array}$ & $\begin{array}{c}3 \text { or } 4 \\
(n=168,69.4 \%)\end{array}$ & $\begin{array}{c}\geq 5 \\
(n=16,6.6 \%)\end{array}$ & $P$ \\
\hline \multicolumn{6}{|l|}{ Demographics } \\
\hline Mean age, years (IQR) & $74(65-79)$ & $70(60-82)$ & $74(67-79)$ & $75(68-80)$ & 0.636 \\
\hline Age older than 65 & $182(75.2 \%)$ & $34(58.6 \%)$ & $135(80.4 \%)$ & $13(81.3 \%)$ & 0.004 \\
\hline \multicolumn{6}{|l|}{ Gender } \\
\hline Male & $162(66.9 \%)$ & $32(55.2 \%)$ & $118(70.2 \%)$ & $12(75.0 \%)$ & \multirow{2}{*}{0.085} \\
\hline Female & $80(33.1 \%)$ & $26(44.8 \%)$ & $50(29.8 \%)$ & $4(25.0 \%)$ & \\
\hline \multicolumn{6}{|l|}{ Race } \\
\hline White & $229(94.6 \%)$ & $55(94.8 \%)$ & $158(94.1 \%)$ & $16(100 \%)$ & \multirow{2}{*}{0.599} \\
\hline Other & $13(5.4 \%)$ & $3(5.2 \%)$ & $10(6.0 \%)$ & 0 & \\
\hline \multicolumn{6}{|l|}{ Comorbidities } \\
\hline Hypertension & $134(55.4 \%)$ & $22(37.9 \%)$ & $101(60.1 \%)$ & $11(68.8 \%)$ & 0.007 \\
\hline Coronary artery disease & $141(58.3 \%)$ & $28(48.3 \%)$ & $105(62.5 \%)$ & $8(50.0 \%)$ & 0.131 \\
\hline CABG & $68(28.1 \%)$ & $13(22.4 \%)$ & $51(30.4 \%)$ & $4(25.0 \%)$ & 0.490 \\
\hline Cerebrovascular accident & $22(9.1 \%)$ & $7(12.1 \%)$ & $14(8.3 \%)$ & $1(6.3 \%)$ & 0.639 \\
\hline Dialysis & $4(1.7 \%)$ & $1(1.7 \%)$ & $3(1.8 \%)$ & 0 & 1.000 \\
\hline AF/AFL & $118(48.8 \%)$ & $32(55.2 \%)$ & $78(46.4 \%)$ & $8(50.0 \%)$ & 0.514 \\
\hline Congestive heart failure & $181(74.8 \%)$ & $36(62.1 \%)$ & $131(78.0 \%)$ & $14(87.5 \%)$ & 0.027 \\
\hline Mean LVEF, \% (IQR) & $30(20-40)$ & $35(25-50)$ & $30(20-35)$ & $25(15-35)$ & 0.002 \\
\hline Median follow-up, years (IQR) & $2.0(1.1-3.5)$ & $1.7(0.9-3.1)$ & $2.0(1.2-3.6)$ & $1.7(1.0-3.9)$ & 0.423 \\
\hline \multicolumn{6}{|l|}{ Device Type } \\
\hline Pacemaker & $127(52.5 \%)$ & $24(41.4 \%)$ & 95 (56.6\%) & $8(50.0 \%)$ & $<0.001$ \\
\hline Defibrillator & $72(29.8 \%)$ & $33(56.9 \%)$ & $35(20.8 \%)$ & $4(25.0 \%)$ & \\
\hline Biventricular & $5(2.1 \%)$ & 0 & $5(3.0 \%)$ & 0 & \\
\hline Biventricular-ICD & $38(15.7 \%)$ & $1(1.7 \%)$ & $33(19.6 \%)$ & $4(25.0 \%)$ & \\
\hline Atrial lead & $168(69.4 \%)$ & $21(36.2 \%)$ & $133(79.2 \%)$ & $14(87.5 \%)$ & $<0.001$ \\
\hline \multicolumn{6}{|l|}{ Indication for lead revision } \\
\hline Device malfunction & $21(8.7 \%)$ & $18(31.0 \%)$ & $3(1.8 \%)$ & 0 & $<0.001$ \\
\hline Lead malfunction & $115(47.5 \%)$ & $35(60.3 \%)$ & $76(45.2 \%)$ & $4(25.0 \%)$ & 0.024 \\
\hline Lead recall & $13(5.4 \%)$ & $2(3.5 \%)$ & $11(6.6 \%)$ & 0 & 0.409 \\
\hline Pain & $4(1.7 \%)$ & $2(3.5 \%)$ & $2(1.2 \%)$ & 0 & 0.440 \\
\hline Venous occlusion & $1(0.4 \%)$ & 0 & 0 & $1(6.3 \%)$ & 0.066 \\
\hline
\end{tabular}

Values are presented as counts (percentages), except where noted otherwise.

$A F / A F L$, atrial fibrillation/atrial flutter; $C A B G$, coronary artery bypass graft; ICD, implantable cardioverter-defibrillator; $I Q R$, interquartile range; $L V E F$, left ventricular ejection fraction.

more prevalent with escalating number of leads. As lead burden increased, mean left ventricular ejection fraction (LVEF) also was significantly lower (A: $35 \%$, B: $30 \%, C: 25 \% ; \mathrm{P}=0.002)$. The differences with regard to congestive heart failure and reduced LVEF were to be expected, as patients with advanced left ventricular dysfunction are more often candidates for upgrade to ICD and biventricular devices. This was demonstrated by the higher number of biventricular ICD devices in Group B (19.6\%) and Group C (25.0\%) vs. Group A $(1.7 \%), P<0.001$. The difference in number of biventricular ICD devices between Group B and Group $\mathrm{C}$ was not statistically significant $(\mathrm{P}=0.856)$. The same contrast was found regarding the presence of atrial lead (A: $36.2 \%, B: 79.2 \%, C: 87.5 \%$; $<<0.001$; whereas $\mathrm{P}=0.744$ for $\mathrm{B}$ vs. $\mathrm{C}$ ). Indications for lead revision 
also differed, with more device or lead malfunctions associated with Group A (Table 1).

\section{Adverse Events}

Our study population had 49 total periprocedural or long-term events over the study period, a $20.2 \%$ event incidence (49 events/242 patients). Combined periprocedural and late events occurred more frequently with increasing lead burden (A: $5.2 \%[\mathrm{n}=3]$, B: $23.2 \%[n=39], C: 44.0 \%$ [n=7]; $P=0.001$ ) (Figure 1). Major events were rare, occurring in $3.3 \%$ of patients (8 events/242 patients). Major events were defined as subsequent infection post-lead abandonment $(\mathrm{n}=6)$, cardiac or central venous perforation $(n=2)$, and/or death related to abandoned lead $(n=0)$.

\section{Periprocedural and Inhospital Events}

Slightly less than half of the total events (23/49) occurred during the lead revision periprocedural/ inhospital period. As lead burden increased, the periprocedural/inhospital event rate increased (A: $3.4 \%$ [n=2], B: $10.1 \%$ [n=17], C: $25 \%$ [n=4]; P=0.031) (Figure 2). These complications (Table 2) included pneumothorax (A: $0 \%$ [n=0], B: $0.6 \%$ [n=1], C: $6.3 \%$ $[\mathrm{n}=1] ; \mathrm{P}=0.185$ ), hematoma (A: $0 \%[\mathrm{n}=0], \mathrm{B}: 1.2 \%$ $[\mathrm{n}=2], \mathrm{C}: 0 \%[\mathrm{n}=0] ; \mathrm{P}=1.000)$, spontaneous procedural

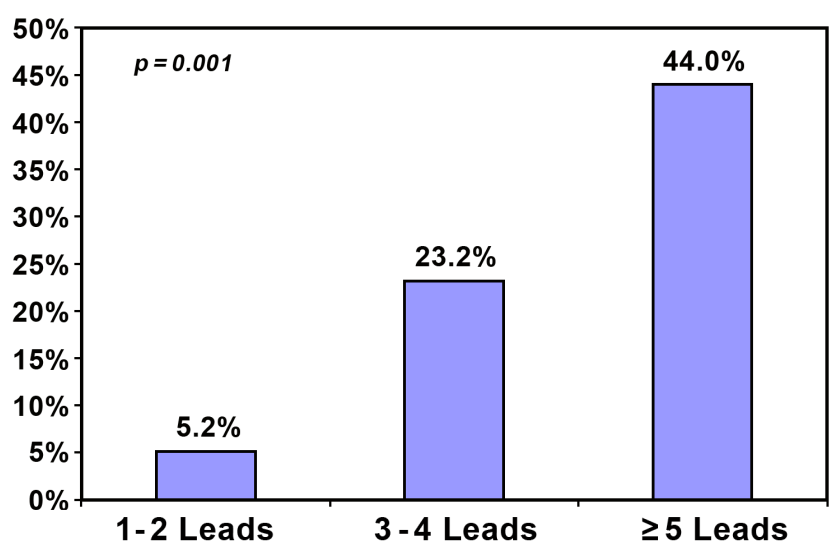

Figure 1. Combined periprocedural and late event rates. Periprocedural events were defined as vein occlusions requiring change in strategy for lead placement, pneumothorax, cardiac or central venous perforation, failure to place new lead, high defibrillation thresholds requiring additional intervention and hematoma. Late events were defined as infection, bleeding, inappropriate implantable cardioverter-defibrillator shock, new atrial arrhythmia and venous thrombosis. arrhythmias requiring treatment $(\mathrm{A}: 0 \%[\mathrm{n}=0], \mathrm{B}: 0.6 \%$ $[n=1], C: 6.3 \%[n=1] ; P=0.185)$ and cardiac or central venous perforation $(A: 0 \%[n=0], B: 1.2 \%[n=2]$, $\mathrm{C}: 0 \%[\mathrm{n}=0] ; \mathrm{P}=1.000)$. Three patients with redundant leads had coronary sinus lead implantation failures (A: $0 \%[n=0], B: 1.8 \%[n=3], C: 0 \%[n=0] ; P=0.651$ ). One patient required additional intervention to attain adequate defibrillation thresholds (A: $0 \%[\mathrm{n}=0]$, B: $0.6 \%[n=1], C: 0 \%[n=0] ; P=1.000)$. Eleven patients (A: $3.4 \%[n=2], B: 4.2 \%$ [n=7], C: $12.5 \%$ $[n=2] ; P=0.280)$ undergoing device upgrade required a redundant lead-related procedural adjustment such as tunneling, use of a different access site or venoplasty for an occluded vessel. There was no procedurerelated or inhospital mortality in any group.

\section{Long-Term Events}

There was a $10.7 \%$ incidence of events (26 events/ 242 patients) during long-term follow-up (Table 3). Infection occurred in 6 patients (A: $0 \%[n=0]$, B: $3.6 \%[n=6], C: 0 \%[n=0] ; P=0.452)$. There were 5 late bleeding episodes (A: $0 \%[n=0], B: 3.0 \%[n=5]$, C: $0 \% \quad[n=0] ; \quad P=0.527)$. Symptomatic venous thrombosis occurred in 3 patients (A: $1.7 \%[n=1]$, B: $1.2 \%[n=2], C: 0 \%[n=0] ; P=1.000)$. Four patients had inappropriate ICD shock (A: $0 \%[n=0]$, B:

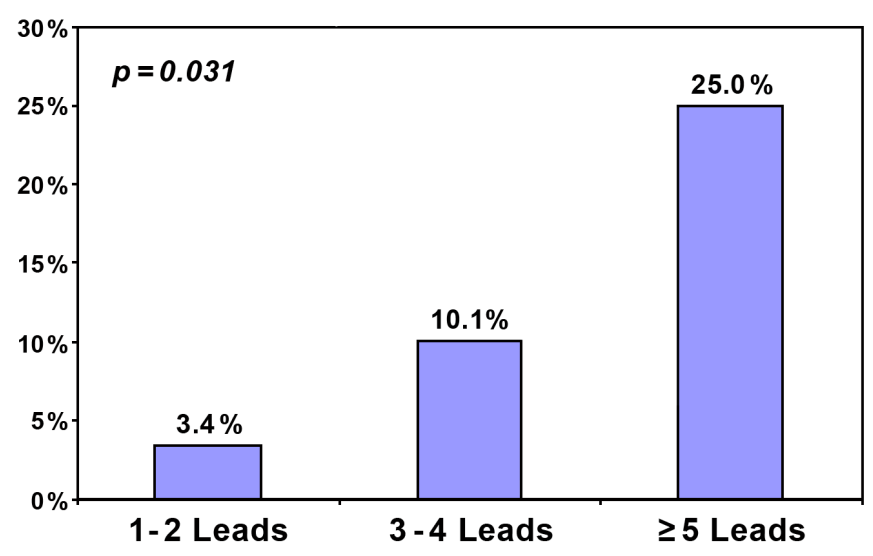

Figure 2. Rates of periprocedural events, defined as vein occlusions requiring change in strategy for lead placement, pneumothorax, cardiac or central venous perforation, failure to place new lead, high defibrillation thresholds requiring additional intervention and hematoma. 
Table 2. Periprocedural events

\begin{tabular}{|c|c|c|c|c|c|}
\hline \multirow[b]{2}{*}{ Variable } & \multirow[b]{2}{*}{$\begin{array}{l}\text { Overall } \\
(\mathrm{N}=242)\end{array}$} & \multicolumn{4}{|c|}{ Number of leads } \\
\hline & & $\begin{array}{c}\leq 2 \\
(n=58)\end{array}$ & $\begin{array}{c}3 \text { or } 4 \\
(n=168)\end{array}$ & $\begin{array}{c}\geq 5 \\
(n=16)\end{array}$ & $P$ \\
\hline Vein occlusion requiring procedural adjustment & $11(4.5 \%)$ & $2(3.4 \%)$ & $7(12.1 \%)$ & $2(12.5 \%)$ & 0.280 \\
\hline Pneumothorax & $2(0.8 \%)$ & 0 & $1(0.6 \%)$ & $1(6.3 \%)$ & 0.185 \\
\hline Central venous or cardiac perforation & $2(0.8 \%)$ & 0 & $2(1.2 \%)$ & 0 & 0.185 \\
\hline Lead placement failure & $3(1.2 \%)$ & 0 & $3(1.8 \%)$ & 0 & 0.651 \\
\hline Hematoma & $2(0.8 \%)$ & 0 & $2(1.2 \%)$ & 0 & 1.000 \\
\hline $\begin{array}{l}\text { Spontaneous procedural unstable arrhythmia } \\
\text { requiring treatment }\end{array}$ & $2(0.8 \%)$ & 0 & $1(0.6 \%)$ & $1(6.3 \%)$ & 1.000 \\
\hline $\begin{array}{l}\text { Failure to attain adequate defibrillation threshold } \\
\text { requiring additional intervention }\end{array}$ & $1(0.4 \%)$ & 0 & $1(0.6 \%)$ & 0 & 1.000 \\
\hline Total events & $\overline{23}(\overline{9} . \overline{5} \%)$ & $2(3.4 \%)$ & $\overline{17}(\overline{10} \overline{10} \overline{1})$ & $\overline{4}(25.0 \overline{\%})$ & $\overline{0} \overline{0} \overline{31}$ \\
\hline
\end{tabular}

Values are presented as counts (percentages).

Table 3. Distribution of late events

\begin{tabular}{|c|c|c|c|c|c|}
\hline \multirow[b]{2}{*}{ Variable } & \multirow[b]{2}{*}{$\begin{array}{l}\text { Overall } \\
(\mathrm{N}=242)\end{array}$} & \multicolumn{4}{|c|}{ Number of leads } \\
\hline & & $\begin{array}{c}\leq 2 \\
(n=58)\end{array}$ & $\begin{array}{c}3 \text { or } 4 \\
(n=168)\end{array}$ & $\begin{array}{c}\geq 5 \\
(n=16)\end{array}$ & $P$ \\
\hline Infection & $6(2.5 \%)$ & 0 & $6(3.6 \%)$ & 0 & 0.452 \\
\hline Late bleeding & $5(2.0 \%)$ & 0 & $5(3.0 \%)$ & 0 & 0.527 \\
\hline Inappropriate ICD shock & $4(1.7 \%)$ & 0 & $3(1.8 \%)$ & $1(6.3 \%)$ & 0.188 \\
\hline New atrial arrhythmia & $8(3.3 \%)$ & 0 & $6(3.6 \%)$ & $2(12.5 \%)$ & 0.045 \\
\hline Venous occlusion & $3(1.2 \%)$ & $1(1.7 \%)$ & $2(1.2 \%)$ & 0 & 1.000 \\
\hline Total events & $26(10.7 \%)$ & $1(1.7 \%)$ & $22(13.1 \%)$ & $3(18.8 \%)$ & 0.031 \\
\hline
\end{tabular}

Values are presented as counts (percentages). ICD, implantable cardioverter-defibrillator.

$1.8 \%[\mathrm{n}=3], \mathrm{C}: 6.3 \%[\mathrm{n}=1] ; \mathrm{P}=0.188)$. New atrial arrhythmia presented in 8 patients (A: $0 \%[\mathrm{n}=0]$, B: $3.6 \%[n=6], C: 12.5 \%[n=2] ; P=0.045)$. There was no clinically apparent cardiac or central venous perforation. Combined long-term device-related events significantly increased with greater lead burden (A: $1.7 \%[n=1], B: 13.0 \%[n=22], C: 18.8 \%[n=3]$; $\mathrm{P}=0.031$ ) (Figure 3).

\section{Device-Related Readmission}

Patients with increased lead burden had significantly increased frequency of device-related unplanned readmission (A: 3.5\%, B: 18.5\%, C: 37.5\%; $\mathrm{P}=0.002$ ) (Figure 4). Cause for admission included infection (occurring after a lead was abandoned), new arrhythmia and inappropriate ICD therapies.

\section{All-Cause Mortality}

There were 54 deaths during the follow-up period. No deaths were secondary to device-related issues. Longterm all-cause mortality was not significantly different among the groups (A: $17.2 \%, \mathrm{~B}: 23.8 \%, \mathrm{C}: 25.0 \%$; $\mathrm{P}=0.567$ ) (Figure 5).

\section{DISCUSSION}

The management of infected cardiac rhythm devices is straightforward, with lead extraction being the preferred strategy due to the significantly higher 


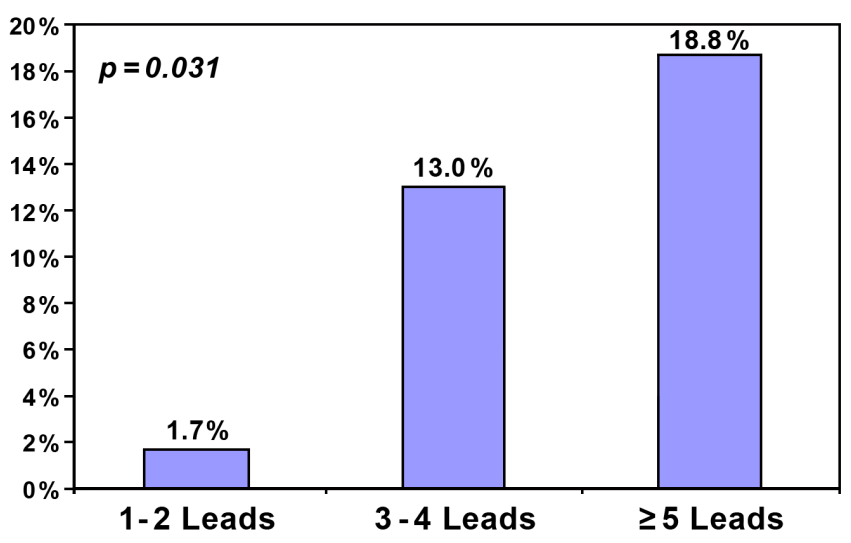

Figure 3. Rates of late events, defined as infection, bleeding, inappropriate implantable cardioverterdefibrillator shock, new atrial arrhythmia and venous thrombosis.

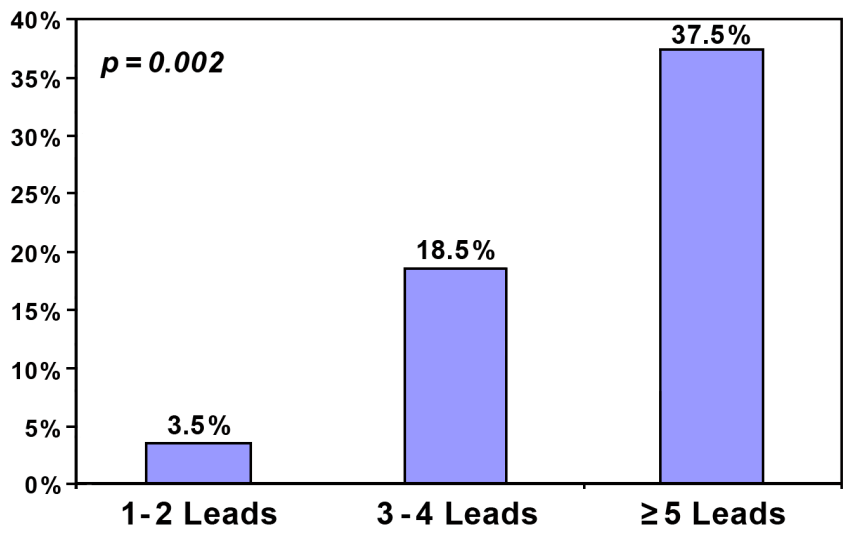

Figure 4. Device-related readmissions. Admissions included patients with infections (occurring after a lead was abandoned), new arrhythmia and inappropriate implantable cardioverter-defibrillator therapies.

mortality rate with medical therapy alone. ${ }^{6,7}$ However, whether to leave sterile pacemaker and ICD leads in place remains controversial. This retrospective study of a single institutional experience had an approximate event rate of $20.2 \%$ (3.3\% major event rate) over 2-year median follow-up, with no difference in mortality among the groups based on lead burden. Most studies in the literature have reported a low complication rate relating to the continued presence of sterile nonfunctioning leads. An observational study that followed 433 patients with abandoned pacemaker leads over a 21-year period showed a 5.5\% complication rate. $^{8}$ Another retrospective study that examined patients with retained infected and noninfected leads

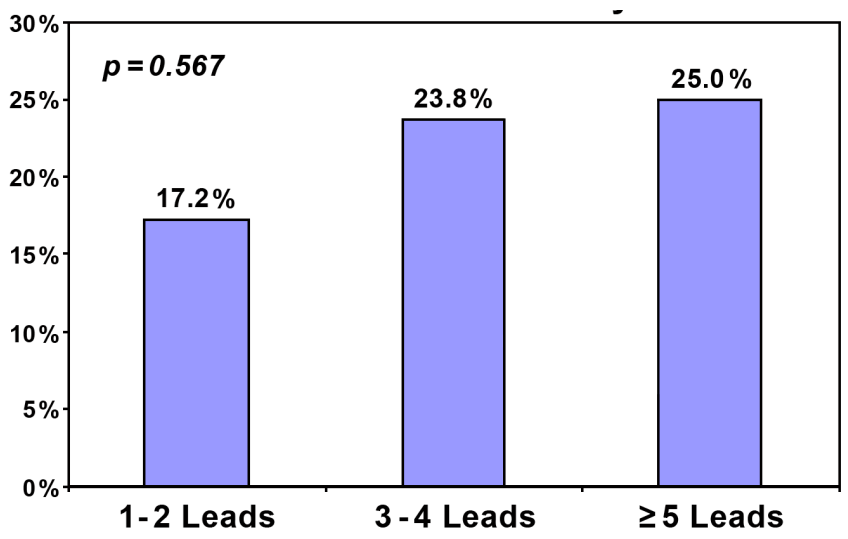

Figure 5. Overall all-cause mortality (obtained from Social Security Death Index).

showed a 42\% (22/53 patients) major complication rate with retained infected leads, but a 3\% (2/66) major complication rate in sterile leads abandoned because of electrical failure. ${ }^{7}$ A study of 152 patients with retained pacemaker leads and mean follow-up of 47.6 months recorded one major event, an infection resulting in death during the attempted extraction procedure. ${ }^{9}$ However, a single-center European retrospective study of 60 patients with nonfunctioning sterile pacemaker leads reported a complication rate of $20 \%$ over longterm follow-up, ${ }^{10}$ similar to our institutional experience. Our study differed from previous investigations in that it included both patients with ICD and pacemaker leads. In the earlier studies, device therapy was mainly indicated for bradyarrhythmias, as the efficacy of ICD was not proven at that point; thus, most lead systems were pacemakers. One recent study addressed 101 abandoned leads in 78 ICD patients and confirmed the safety of these abandoned leads. ${ }^{11}$ However, it did not address outcomes in patients with higher lead burden at a given time.

Arguments for more aggressive use of lead extraction are based on prevention of future complications, such as infection, lead-lead interaction, tricuspid regurgitation and venous thrombosis, and preservation of venous access to simplify future procedures. While our study did not show an overall significant number of individual events related to infection, lead interaction or venous thrombosis, nor did it attempt to measure frequency of tricuspid regurgitation, it did show a greater number of combined periprocedural complications associated with 
increased number of leads. Patients undergoing repeat procedures such as generator change or device upgrade were more likely to experience minor complications such as hematoma and pneumothorax, but these patients had no significant increase in mortality or major morbidity rates. However, lead extraction may have been a better option in the 11 patients (A: 2, B: 7, C: 2) needing procedural adjustments (e.g. tunneling of a vein, use of an alternate access site, venoplasty of an occluded vessel) during device upgrade related to a redundant lead. If a lead is removed and then replaced by a new lead in the same vein, the contralateral vein is preserved for potential future access. However, there is no evidence that extraction of a lead, with the concomitant insult to the endothelium, will not lead to a greater likelihood of thrombosis in that vein postextraction.

There was a $10.7 \%$ incidence rate of events that occurred outside of elective periprocedural periods; incidents included device-related infection $(n=6)$, late bleeding $(\mathrm{n}=5)$, symptomatic venous thrombosis $(n=3)$, inappropriate ICD shocks $(n=4)$ and new atrial arrhythmias $(n=8)$. Other than venous thrombosis, it is unclear whether these late events were directly related to the presence of a redundant lead. Some of the long-term complications seen in other studies, such as lead migration, erosion and perforation, were perhaps not seen in our study because all abandoned leads were capped and secured, which was not always the strategy used in older studies. This study is limited in its assessment of long-term follow-up because our median follow-up was 2 years, significantly less than the 20-year follow-up of prior studies.

It is essential to mention that Group $C$ ( $\geq 5$ leads) had higher baseline comorbidities (older population, history of hypertension, more congestive heart failure and lower left ventricular function). Therefore, some of the periprocedural and late events could be caused by these comorbidities rather than the lead burden itself. In terms of periprocedural events, vein occlusion requiring procedural adjustment, pneumothorax and spontaneous procedural arrhythmia requiring treatment were the three factors showing higher events in Group C. Theoretically, vein occlusion was most likely due to the lead burden; pneumothorax could be related to the lead burden, vein occlusion or possibly older age; and spontaneous arrhythmia requiring treatment could be due to presence of hypertension, heart failure or left ventricular dysfunction in addition to lead burden. The two main factors driving the higher rate of late events in Group C were inappropriate ICD shocks and new atrial arrhythmia. Both of them could be related to lead burden, but also to the cardiac condition of patients (e.g. hypertension, congestive heart failure, lower LVEF). The presence of more new atrial arrhythmia in Group C compared to Group B was not related to atrial leads, as there was no statistical difference between these two groups regarding the presence of atrial lead. Further studies of larger number of patients with more than 5 leads are necessary to evaluate these findings, although this could be difficult to achieve through a single institution.

Whether lead extraction and its $0.4-0.8 \%$ risk for death or emergent cardiac surgery is a better option than lead abandonment is uncertain. Optimal management strategy will likely vary from patient to patient and facility to facility. The only modifiable risk factor for complications from lead extraction is operator experience. ${ }^{12}$ Centers with limited operator experience will likely prefer an observation strategy. Another aim in the argument for extracting leads is to maintain long-term venous access. Young patients who will likely require several future procedures and be exposed to superfluous leads for longer periods of time may benefit from lead extraction strategy. Patients with venous access issues also may benefit from a lead extraction strategy.

\section{CONCLUSIONS}

The results of this study show that complications associated with redundant sterile leads are not necessarily rare, but that major complications and mortality related to superfluous leads are not common. However, patients who undergo additional electrophysiologic procedures are subjected to increased minor complications and access issues during future lead implantations. A lead management strategy of abandonment and observation is likely the best alternative for patients with four or fewer leads who will not require more than one future procedure. On the other hand, in patients with a long life expectancy who are likely to require multiple repeat procedures, have access issues or have more than four leads, a better strategy than abandoning the lead needs to be strongly considered. 


\section{Patient-Friendly Recap}

- Physicians will often recommend a pacemaker or cardiac defibrillator to manage serious heart rhythm disorders.

- Due to recent advances in technology, the number of these device implantations has dramatically increased.

- Flexible wires called "leads" are used to connect these devices to the heart, and typically run through a vein.

- Some patients undergo multiple implant procedures over the course of their lives, and old leads, while sterile, cease to be used with the new devices.

- The authors report that removing these unused leads may not be necessary. However, leaving old leads in place can lead to minor complications or limit access to needed veins for future procedures.

\section{Acknowledgments}

The authors gratefully acknowledge Brian Miller and Brian Schurrer of Aurora Sinai Medical Center for their help with figures.

\section{Conflicts of Interest}

None.

\section{REFERENCES}

1. Hammill SC, Kremers MS, Stevenson LW, et al. Review of the registry's fourth year, incorporating lead data and pediatric ICD procedures, and use as a national performance measure. Heart Rhythm. 2010;7:1340-5.

2. Epstein AE, DiMarco JP, Ellenbogen KA, et al. ACC/AHA/ HRS 2008 guidelines for Device-Based Therapy of Cardiac Rhythm Abnormalities: executive summary. Heart Rhythm. 2008;5:934-55.

3. Wilkoff BL, Love CJ, Byrd CL, et al. Transvenous lead extraction: Heart Rhythm Society expert consensus on facilities, training, indications, and patient management: this document was endorsed by the American Heart Association (AHA). Heart Rhythm. 2009;6:1085-104.

4. Venkataraman G, Hayes DL, Strickberger SA. Does the riskbenefit analysis favor the extraction of failed, sterile pacemaker and defibrillator leads? J Cardiovasc Electrophysiol. 2009;20:1413-5.

5. Jones SO 4th, Eckart RE, Albert CM, Epstein LM. Large, single-center, single-operator experience with transvenous lead extraction: outcomes and changing indications. Heart Rhythm. 2008;5:520-5.

6. Phibbs B, Marriott HJ. Complications of permanent transvenous pacing. N Engl J Med. 1985;312;1428-32.

7. Parry G, Goudevenos J, Jameson S, Adams PC, Gold RG. Complications associated with retained pacemaker leads. Pacing Clin Electrophysiol. 1991;14:1251-7.

8. Suga C, Hayes DL, Hyberger LK, Lloyd MA. Is there an adverse outcome from abandoned pacing leads? J Interv Card Electrophysiol. 2000;4;493-9.

9. Furman S, Behrens M, Andrews C, Klementowicz P. Retained pacemaker leads. J Thorac Cardiovasc Surg. 1987;94:770-2.

10. Böhm A, Pintér A, Duray G, et al. Complications due to abandoned noninfected pacemaker leads. Pacing Clin Electrophysiol. 2001;24:1721-4.

11. Glikson M, Suleiman M, Luria DM, et al. Do abandoned leads pose a risk on implantable cardioverter-defibrillator patients? Heart Rhythm. 2009;6:65-8.

12. Hamid S, Arujuna A, Ginks M, et al. Pacemaker and defibrillator lead extraction: predictors of mortality during follow-up. Pacing Clin Electrophysiol. 2010;33:209-16.

(C) 2015 Aurora Health Care, Inc. 